\title{
A report on the CD-ROM Teleconference
}

On April 27, 1988, a national teleconference on the use of CD-ROM technology in the library was held under the auspices of the Community and Junior College Libraries Section of the Association of College and Research Libraries and the Community College Association for Instruction and Technology/AECT. Initiated by the CJCLS Committee on Integrating New Technologies into Learning Resource Centers, it was viewed by almost 11,000 people at 335 sites in the United States and Canada. Forty percent of the viewers were at two-year colleges, twenty-seven percent at universities, and fourteen percent at four-year colleges. Other sites were elementary and secondary school, public and special libraries, and library system headquarters. Among the special libraries and library systems participating were NASA, AT\&T's Murray Hill Research Center, the Naval Research Laboratory, the National Agriculture Library, the Congressional Information Service, and the North County Library Loop (Minnesota).

The conference was intended to serve the following purposes:

- Supply an overview of CD-ROM technology and workstations;

-Provide in-depth information about available products and costs;

- Present an overview of library receptivity to CD-ROM products;

- Outline the latest trends in CD-ROM product development and marketing;

- Suggest a variety of uses for CD-ROM in library/LRC environments;

-Address cost structures and implementation issues;

- Stimulate innovative uses of CD-ROM technology for instructional support;

- Promote the participation of library/LRC personnel in shaping the future of this exciting information technology.

The teleconference, made possible through the collaboration of vendors interested in demonstrating their products, was organized at Oakton Community College in Des Plaines, Illinois. The fact that it was interactive made possible questions from the audience that could be directed to the various speakers and panelists featured in the teleconference. Many of the site coordinators used the teleconference for internal staff development, while others incorporated it into a larger program. They brought speakers or vendors to their campuses to supplement the conference and to provide handson experience for those present.

The more than 8,000 individuals who submitted postconference evaluations were in the main highly appreciative of the program. The majority of respondents said they watched the telecon- ference to acquire an overview of CD-ROM technology, learn about how it is being used in libraries, identify vendors and their products, and gain information about initial and maintenance costs. Many of these people had little prior knowledge of CD-ROM technology. They regarded the teleconference as a convenient, inexpensive learning experience that contributed to their professional growth. Indeed, the conference reached many professionals generally unable to attend national, regional, or even state workshops or specialized seminars.

Some viewers already familiar with the technology, thought that the teleconference was too elementary and lacked depth. Nevertheless, the teleconference, in assembling a national audience, provided a basis for continuing discussion of CDROM issues. Among the issues that require further discussion are: utilization of CD-ROM products in instruction; development of a user's perspective on future applications; and the possibility of forming a user's cooperative to encourage standardization, the development of compatible systems, and reduction of costs.

In retrospect, it is clear that the teleconference was a useful experiment. It demonstrated the very substantial potential teleconferencing offers for continuing education for library and media personnel. The substantial initial cost of organizing a teleconference is offset by the low per capita cost for the large audiences that can be served. In an age when restricted institutional budgets contain limited funds for travel and lodging at distant professional conventions, teleconferencing as a tool for staff development and professional exchange appears attractive. Many of those viewing the April 27 teleconference recognized this potential and suggested a variety of subjects, including a second teleconference on CD-ROM library automation and networking. A full evaluation of the teleconference will appear in a forthcoming issue of the Community and Junior College Library Journal. - Eileen Dubin, Director of Library Services, Stockton State College, and Past Chair of CJCLS.

\section{Poster session applications due}

The deadline for the receipt of applications for poster sessions at the ACRL Fifth National Conference is November 1, 1988. An abstract of the session must be submitted on the official form, available from the ACRL office. Poster sessions may present research findings, innovative programs, or solutions to problems. 


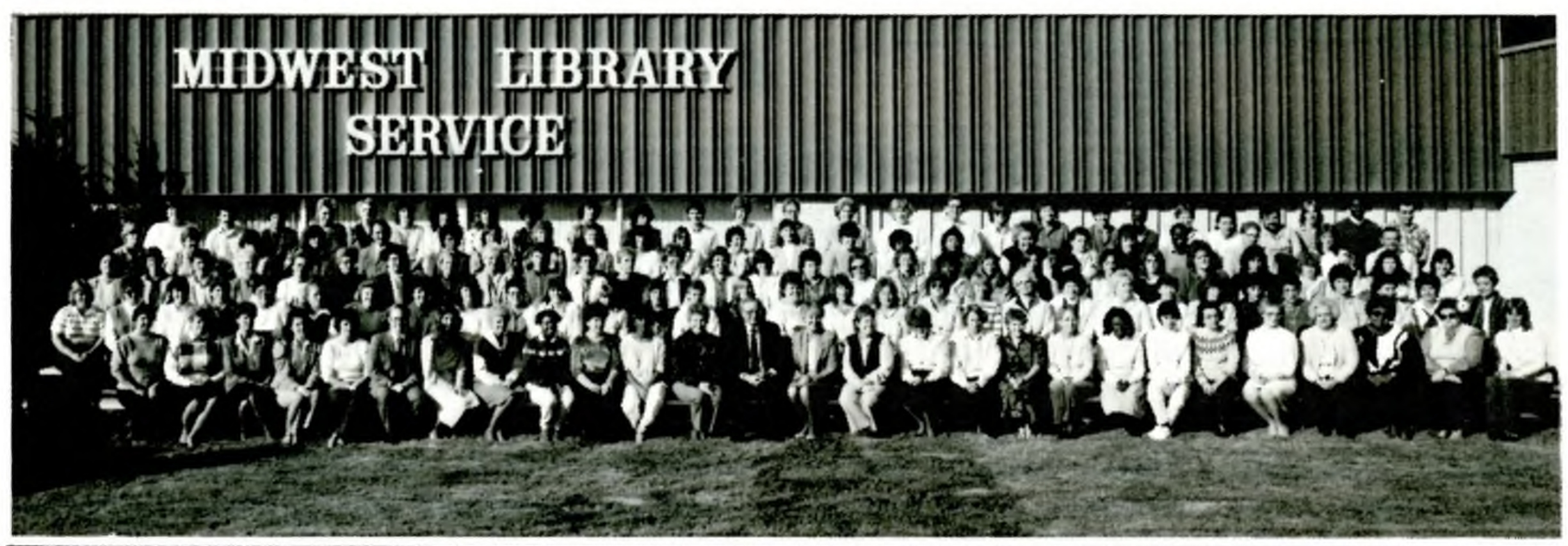

\section{When You Call MLS, The Whole Team Answers!}

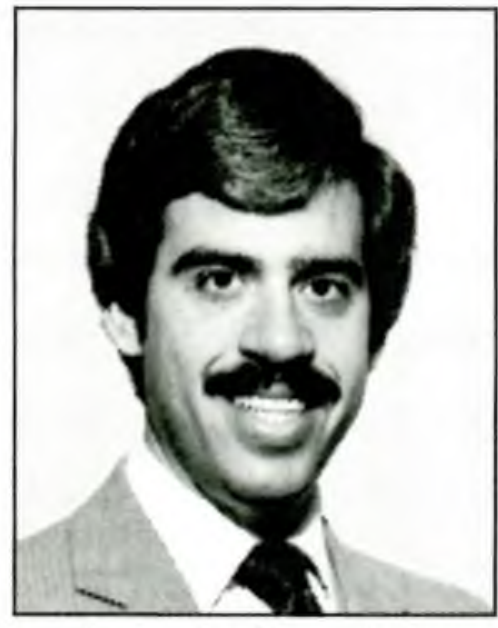

Jay Askuvich General Sales Manager

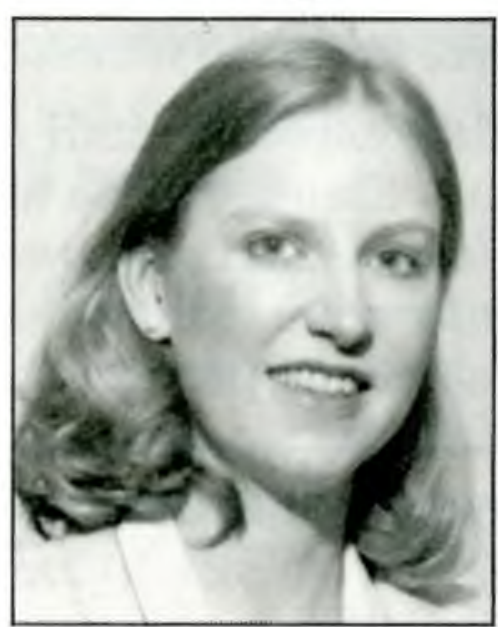

Eva Mahanna Southwest

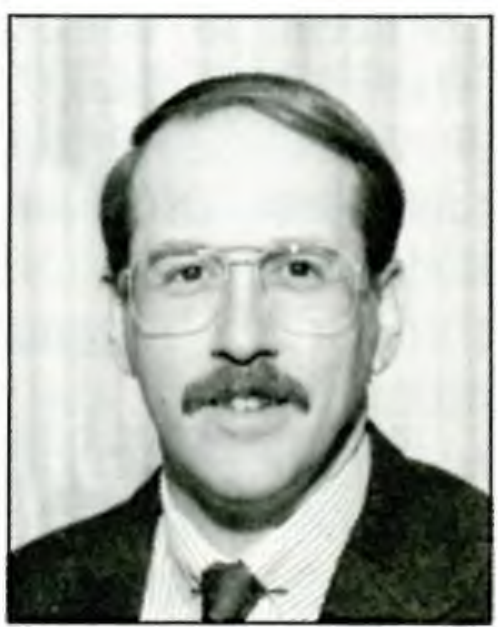

Scott Schmidt Midwest

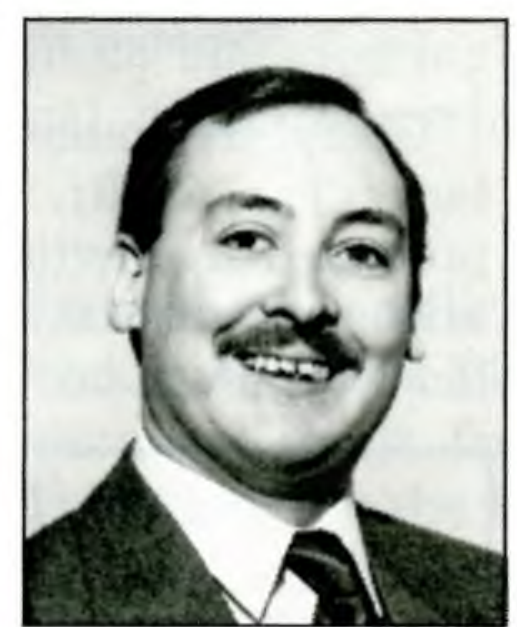

Forrest Link Northeast

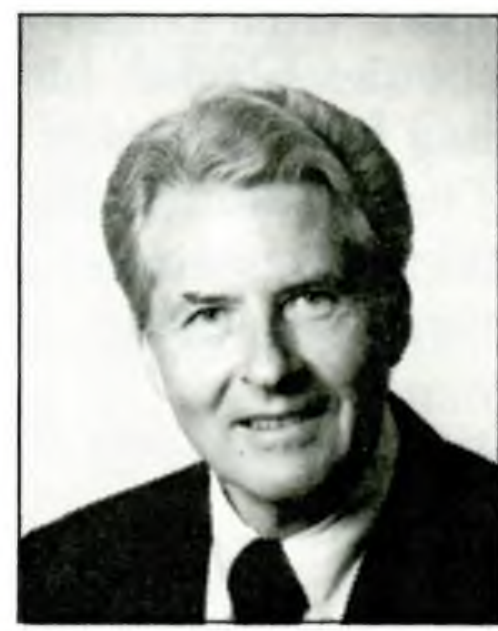

Carl Dorr Southeast

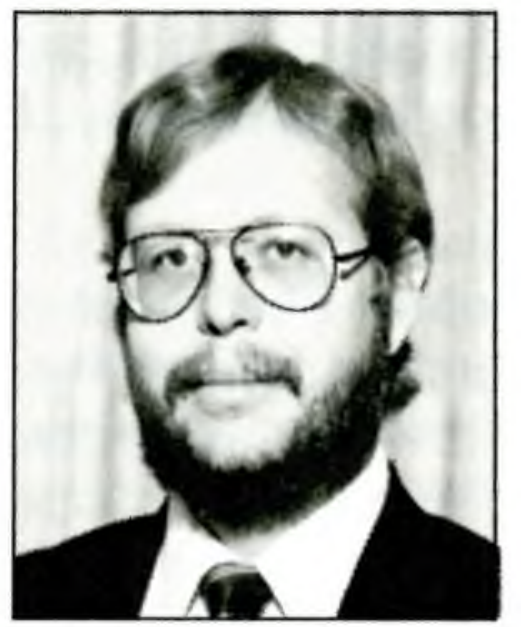

Kim Anderson Mountain Plains

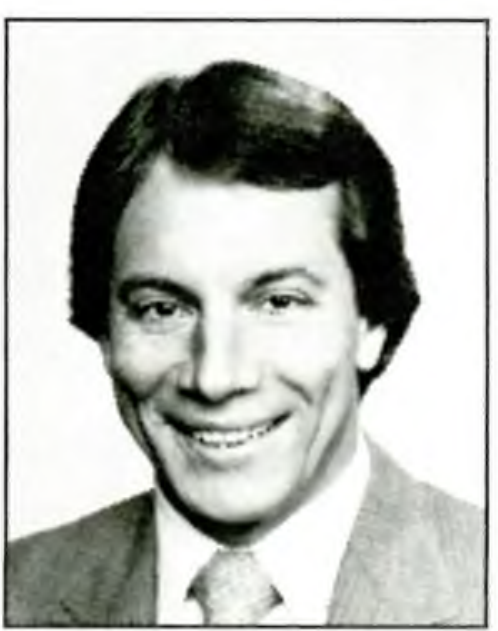

Lawrence Nagel West

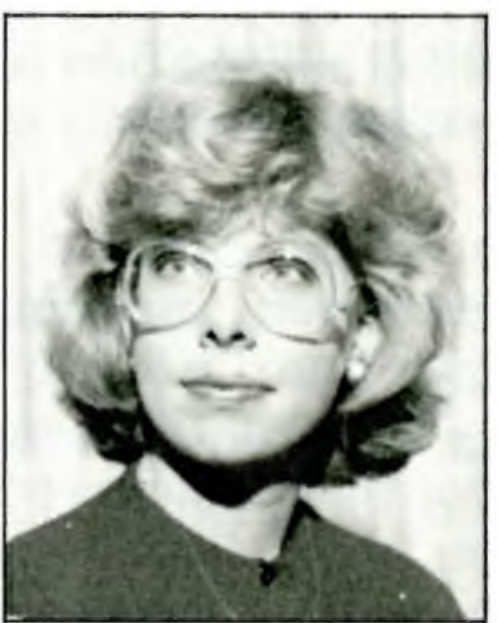

Lorraine Best Canada

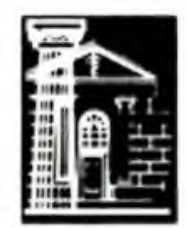

\section{Midwest Library Service}

11443 St. Charles Rock Road Bridgeton, MO 63044, USA

Call toll-free 1-800-325-8833

Missouri librarians call toll-free 1-800-392-5024

Canadian librarians call toll-free 1-800-527-1659 